cylinder of nitrous oxide in my bag. During the past six months I have not nsed nitrous oxide once in surgical work but have invariably employed the ethyl chloride-ether sequence in preference. I use ethyl chloride every day and often many times a day. I regard it as a very valuable addition to the anæsthetist's repertoire and I am quite sure that it has come to stay and will take a front place among anæsthetic agents in the future. It has been used as largely in Edinburgh as in any medical school during the past few months I think. It is used almost exclusively in the ear and throat wards of the Royal Infirmary and also in the dental department latterly. I am also proud to say that on my advocacy a gentleman of much wider anæsthetic experience than myself started using it in one of the Metropolitan hospitals and has since written me with favourable comments.

What has kept back ethyl chloride has been the lack of a suitable inhaler. There are several very good patterns on the market now, however, and with any of these good results can be obtained. In THE LANCET of June 13th (p. 1677), July 18th (p. 168), and Oct. 17th (p. 1087), special inhalers, all based on much the same principle, were described by Mr. R. H. Jocelyn Swan, myself, and Mr. G. W. B. Daniell respectively, while in the issue of April 4th (p. 952) of this year Dr. W. J. McCardie expresses his preference for Ormsby's inbaler. I notice to-day in the new English edition of Kocher's "Operative Surgery" just published, that the anthor remarks that he tried ethyl chloride as a general anæsthetic "several years ago with ungratifying results"this being doubtless due to the use of Breuer's mask (mentioned in a previous paragraph) - a most unsuitable inhaler in every way.

Will you pardon me if at the risk of repetition I sum up in a few sentences the views $I$ have as to the value of ethyl chloride at the present time? 1 . It is a pleasant anæsthetic to inhale, extremely rapid in action, very portable, and inexpensive. 2. It compares favourably with nitrous oxide as regards induction of anæsthesia and available period; it produces no cyanosis when used in suitable doses and necessitates the carrying of no heavy and cumbersome impedimenta. The advantage of this to the general practitioner and dentist in the country is obvious. 3. The technique of the administration is very simple. 4. While not as safe as nitrous oxide in the hands of the unskilled we are justified in concluding from the material available that it is safer than ether, all things considered, and much safer than $\mathrm{CHCl}_{3}$ or bromide of ethyl. 5. It can be safely readministered at one sitting, this being a further point in its favour over bromethyl. 6 . It is not usually followed by marked after-effects. 7. It is preferable to nitrous oxide when the patient is very young, very old, or anæmic, while those who are suffering from cardiac, renal, or lung affections take it quite well. 8 . It is in no way to be preferred to $\mathrm{CHOl}_{3}$ or ether for prolonged anæsthesia but may be used with advantage merely to induce anæsthesia which is maintained either with $\mathrm{CHCl}_{3}$ or ether 9. For minor surgery, throat operations, and the extraction of teeth it is the best anæsthetic available at the present time. 10. Pure ethyl chloride, sold as such, is always preferable to proprietary preparations and to mixtures such as somnoform. 11. In conclusion, I think one of the strongest claims of ethyl chloride to being considered a fairly safe anæsthetic lies in the fact that during the past 12 months it has been experimented with wholesale throughout the country and yet no death has been recorded. I think it quite possible that we may hear of one or two from time to time now as the anxsthetic becomes more widely used, and often by quite unskilled and inexperienced persons, but that should not blind us to the real merits of the drug when used with reasonable precautions.

Edinburgh, Nov. 25th, 1903 I am, Sirs, yours faithfully, THOMAS D. LUKE.

* * We have already expressed our regret to Dr. Luke for the delay that has occurred in the review of his book. Guides to any progressive branch of science speedily pass out of date.-ED. L.

\section{TYPHOID FEVER.}

To the Editors of THE LANOET.

SIRS,-In your issue of Nov. 21st, p. 1416, you publish a clinical lecture on Typhoid Fever by Dr. Seymour Taylor which invites criticism. This no doubt Dr. Taylor expects, for he admits at the outset that his remarks are based entirely on clinical experience (? 56 cases) and may be erroneous. First as to what Dr. Taylor calls the predisposing causes but which I should prefer to designate the primary etiological factors. I have dealt with the flood theory elsewhere in the paper ${ }^{1} \mathrm{I}$ had the honour of reading before the Epidemioogical Society in April last. This flood theory has received the strong support of two such eminent sanitarians as the late Dr. Oorfield and Mr. Shirley F. Murphy, but I contend that the evidence on the whole is against its being more than a minor factor. For instance, do not floods occur as a general rule as much in February as in any other month of the year? Yet the incidence of typhoid fever in London and the Thames Valley is then at its yearly minimum. Dr. Taylor says : "I shall be interested to read the returns of the incidence of enteric fever in the watershed of the Thames during the wet summer and autumn of this year." He can at any rate find the vital statistics of London month by month in your columns, and the returns for October, 1903, are to be found in the same issue of your valuable journal in which appears his own lecture (vide p. 1456). He will find there that "the 49 fatal cases of enteric fever were 28 below the corrected average number." Again, at the Metropolitan Asylums Board hospitals, "the weekly admissions averaged 44 , against 18,27 , and 40 in the three preceding months." Compare these with the weekly admissions in October, 1902, which " averaged 59, against 49, 38, and 63 in the three preceding months." 2 These figures indicate that London, at any rate, has enjoyed a much smaller incidence of typhoid fever this year than last year and I am inclined to think than for many previous years.

On the other hand, these figares lend considerable support to my own theory that the seasonal incidence of typhoid fever is very largely a mere coincidence with the seasonal consumption of infected shell-fish. London has suffered much less this year because of the shell-fish scare created last autumn and winter and the consequent smaller consumption, on the one band, and the greater efforts put forth by the various metropolitan sanitary authorities, aided by the Worshipful Company of Fishmongers, to keep off the London markets shell-fish from obviously polluted sources, on the other hand. They, of course, have not been entirely successful in this but they have certainly accomplished a great deal, and in my judgment the immediate result is the marked decline in the incidence of typhoid fever. As undoubtedly some polluted shell-fish bave been sold in London even this year and, moreover, as visitors to the various seaside resorts have in large numbers indulged in shell-fish while away (returning to develop typhoid fever in the metropolis) the London figures do not yet show the real proportion of typhoid fever due to shell-fish. It is my opinion that a very large proportion of the number of cases which have occurred this autumn are still traceable to shell-fish and that the satisfactory diminution already noted by no means represents the actual proportion of typhoid fever due to shell-fish. Other sources of typhoid fever in the autumn which must not be overlooked are uncooked vegetables and other foods which have been exposed to pollution in some form and perhaps in this direction the flood theory may be of some account.

As to the next primary etiological factor-the soil, or personal factor-there can, of course, be no two opinions as to its being an important one in the individual case, but it can hardly rank as a seasonal factor, the temperature of the human body being about the same all the year round. As to Dr. Taylor's remarks on relapse and recrudescence, I certainly am among those who can dispute his deductions and I can base my own deductions on 110 cases (with only eight deaths, two of these being admitted moribund) under my own care during the last 27 months and 50 additional cases which were under my observation, though not under my personal care, during the same period. I shall publish my own deductions in a separate paper on another occasion merely stating here that they do not coincide with those of Dr. Taylor.

As to treatment I am very interested in Dr. Taylor's use of pulvis hydrargyri cum cretâ. I venture to think that this drug has probably not only a direct antiseptic action but an even more important indirect antiseptic action in promoting the flow of that natural intestinal antiseptic, bile. I can quite believe that both Dr. John Harley and Dr. Taylor have adopted this method of medication with satisfaction; I have myself employed hydrargyri subchloridum in some of my cases with satisfaction, but I have not made it by any

1 Transactions of the Epidemiological Society, 1903. 2 THE LANCET, Nov. 15th, 1902, p. 1347, 
means a routine method. In any case mercury in small doses commends itself to me as a medicament in typhoid fever in the hands of a judicious physician.

I am, Sirs, yours faithfully,

J. T. C. NASH, M.D. Edin., \&c.,

Medical Officer of Health, Southend-on-Sea, and Medical Superintendent of the Borough

Nor. 23rd, 1903. Ferer Hospital.

\section{To the Editors of THE LANCET.}

SIRS, - I was much interested in reading Dr. Seymour Taylor's clinical lecture on Typhoid Fever published in THE LANCET of Nov. 21st (p. 1410). In speaking of the recrudescence of the fever he makes the remark that a rise of temperature in the later stages of the disease frequently follows the administration of an enema. I have a case in point at present. My patient, with a temperature of $99^{\circ} \mathrm{F}$. at the end of the third week and no action of the bowels for four days, his illness having been characterised by constipation rather than by diarrhoea, was ordered a simple enema of soap-and-water. Daring the next 24 hours his temperature rose to $103^{\circ}$ and remained such for 12 hours and then dropped to $99^{\circ}$. I offered an explanation at the time that in absence of any other cause the rise of temperature was due to the liberation of toxins owing to the disturbance caused by the enema. Whether this explanation was the right one puzzled me much till I read Dr. Taylor's paper in which he explains the rise of temperature as due to the liberation of toxins.

I am, Sirs, yours faithfully,

Stamford-hill, N., Nov. 21st, 1903. W. A. Milligan.

\section{THE SUCCESSFUL TREATMENT OF FEW CASES OF LUPUS. To the Editors of THE LANOET.}

SiRs,-May I be allowed to comment upon Mr. C. S. Bowker's interesting article, the Successful Treatment of a Few Cases of Lupus, which appeared in THE LANCET of Nov. $14 \mathrm{th}, \mathrm{p} .1353$. I agree that for suitably situated circumscribed patches of lupus complete excision is the most efficient and the quickest method of treating this disease and a 1 near scar is preferable to a superficial and large scar in all cases. In my hands, like those of $\mathrm{Mr}$. Bowker, cases so treated have been absolutely free from recurrence. I have removed as many as five foci at one time by excision under general anæsthesia. I, however, fail to see the necessity of following up this operation by a course of tuberculin injections, presuming, of course, that all the foci have been completely removed. I should like to ask Mr. Bowker what is his raison d'etre for the injection of arsenic, as such after-treatment is, in my experience, quite unnecessary. In very extensive and long-standing cases of lupus injections of Koch's tuberculin, either the old or the new, when persevered in, have been followed by excellent, and perhaps I may even say brilliant, results, both as regards the cosmetic appearances and the absence of return. I am now largely using the modified Finsen light and the $x$ rays and have seen numerous most satisfactory cures in the hands of other medical men by this means, but I am doubtful if the results obtained by this treatment are superior to those from tuberculin. After the old tuberculin injections the temperature in my cases has occasionally risen to $103^{\circ} \mathrm{F}$, but with the new tuberculin I have never, except in the rarest instances, obtained a temperature reaching $101^{\circ}$. The notes lie before me of a most extensive case of lupus involving the whole of the face excepting the top of the forehead, perforating the septum nasi, destroying part of the alæ nasi, affecting the hard palate, and as the results of its old cicatrising action upon the skin practically crippling the use of the right hand. Under Koch's new tuberculin this patient has immensely improved and I know of no single remedy which could have, in so extensive a case, brought abont equally satisfactory results.

In my opinion the value of the "light" treatment depends upon its efficacy and painlessness ; even children can be easily induced to submit to it until practically cured. The results of "excision" are perfect and speedy ; but there are still some very extensive cases of lupus involving perhaps many different parts of the mucous membrane and skin in which the injections of "tuberculin" are of the highest value.

Wigan, Nov. 17th, 1903.

\section{MEETING OF LICENTIATES OF THE SOCIETY OF APOTHECARIES.}

\section{To the Editors of THE LANCET.}

SIRs,-Kindly permit me to call attention to a notice which appears in your advertisement columns of a meeting of Licentiates which is to be held at the Apothecaries' Hall, Blackfriars, at 4.30 P.M. on Dec. 1st next.

Oxford, Nov. 21st, 1903

$$
\text { I am, Sirs, yours faithfully, }
$$

A. RIVERS-WILLSON.

\section{THE FUTURE OF ST. BARTHOLOMEW'S HOSPITAL.}

To the Editors of THE LANCET.

SIRS, - I must decline to wade through the letter in your issue of Nov. 21st, signed "A St. Bartholomew's Man," as I never attach any value to anonymous communications and in this particular one most of the assumptions are incorrect and do not bear upon the point from which 1 do not intend to be drawn, viz. :-1. Shall St. Bartholomew's Hospital be rebuilt upon Sir Henry Burdett's plan or upon a plan advocated by the medical council, whichever may be the better of the two, at a cost of roughly $£ 600,000$, or shall it be altered and tinkered at a cost of $£ 350,000$ ? 2 . Is the most richly endowed hospital in the world, possessing an income of about $£ 100,000$ per annum (representing at $2 \frac{1}{2}$ per cent. a capital of $£ 4,000.000$ ), justified in asking the public for money if the money is not to be well spent and the effects permanent? 3. If the public find the money asked for, are "they" to decide whether the hospital is (1) to be rebuilt or (2) to be altered, or is the treasurer, who is over 70, and the secretary, who has already exceeded his age-limit, who practically control and manage the hospital, to do as they may think fit? 4. I desire to obtain, if possible, from the medical staff or council a public and almost unanimous expression of opinion stating whether they are satisfied with the plan put forward or whether they consider more ground essential for the building of a proper hospital.

In conclusion, may I say it is my intention to attend at the public meeting to be held at the Mansion House on Jan. 26 th, when the points I have raised will be brought up and the matter finally settled.

I am, Sirs, yours faithfully,

ANDREW MOTION,

Banbury, Nov. 21st, 1903. Chairman of the Cannon Brewery Co.

\section{AUSTRALIAN WINES.}

To the Editors of $\mathrm{TH} \mathrm{B}$ LANCET.

SIRS,-THE LANCET of Oct. 24 th (p. 1173) contains a very interesting leading article headed, "The Vintage and its Relationship to Health." It is with the following sentences in the first paragraph that we propose to deal.

You state: "The wines produced in our colonies, which are invariably richer and stronger than those produced in France or Germany, would lose much of the crude qualities which are characteristic of them were they left to mature. While these wines, be it said, have many excellent points they cannot at present compete as regards delicacy or finesse with the more classic wines of French growth."

In respect to this remark permit us to say that the Australians have not the least intention of competing in types or styles with the wines of France or Germany, of Portugal or Spain, Madeira, Sicily, or any other country in the world. These countries, one and all, produce wines excellent in themselves and specially characteristic. Australian vignerons take a similar position and produce wines characteristic of Australia.

No palate worthy that of a connoisseur would mistake the wines of any of these countries. They are separate and distinct in flavour and in characteristics - as distinct also are the wines of Australia. Therefore, in sampling Australian wines will your readers please taste them on their merits let them consider what to expect from the juice of full ripe grapes produced under sunshine such as is general in Australia, where every leaf is an advantage to the vine, or the sun-oftentimes over $100^{\circ} \mathrm{F}$. in the shade-would scorch the berries. The resulting wine is allowed two years' maturation previous to shipment. The Australian wines most snited to our English climate could never become like the wines of the 